\title{
Fatigue behaviour of a spring: a case study
}

\author{
Nuno Graça ${ }^{1}$ and Paulo M. S. T. de Castro ${ }^{1 *}$ \\ ${ }^{1}$ Departamento de Engenharia Mecânica, Faculdade de Engenharia da Universidade do Porto - FEUP, \\ Rua Dr. Roberto Frias, 4200-465 Porto, Portugal
}

\begin{abstract}
A durability design case study concerning a $U$ spring is presented. For a given geometry of the component, the question was to predict the maximum permissible displacement per cycle whilst ensuring a service life of at least $260 \mathrm{kcycles}$. The stiffness of the spring was evaluated using the finite elements software SolidWorks. As an approximation a linear model was used in the finite elements analysis, which was also compared with an analytical treatment based on Castigliano's theorem. Using a given safety factor, a high cycle fatigue analysis was performed assuming the use of a steel with $650 \mathrm{MPa}$ ultimate tensile strength. The spring is either loaded by an imposed displacement, or it is load free, i.e. load ratio (minimum load / maximum load per cycle), is $R=-1$. An algorithm based on finite fatigue life prediction techniques, the Basquin and Goodman diagrams, and the relationship between ultimate tensile strength and fatigue limit was used and will be briefly presented and discussed. Also, the stress analysis helped to highlight the need for some minor geometry changes. The outcome of the study was the evaluation of the maximum permissible displacement per cycle, as required in the real life case addressed.
\end{abstract}

\section{Introduction}

Due to time dependent damage, as in the cases of corrosion, creep, fatigue or combinations thereof, the prediction of the durability of a component or structure is crucial in many engineering applications. In particular, fatigue damage occurs in materials subjected to cyclic loads and eventually leads to rupture; it is therefore a key consideration in the design of structures as aircraft, metallic bridges, ships, or elements of machines as the spring analyzed in this case study. Fatigue design is a broad science and technology area including many different problems and approaches, including high cycle fatigue, low cycle fatigue and fatigue crack growth studies to mention just major areas. The present case - durability design case study concerning a U spring - falls within the scope of high cycle fatigue studies and use is made of concepts as Basquin law, Goodman diagram and mean stress effect for finite life. These topics are briefly reviewed in the context of failure analysis and prevention by Harris and Jur, [1], and more detailed presentations are made by Lee and Barkey [2], Lee and Taylor [3], or Milella [4].

The finite element method was used to study evaluate the stiffness and stress of the component. 


\section{The design requirements}

For a given geometry of the component, the question was to predict the maximum permissible displacement per cycle whilst ensuring a service life of at least 260 thousand cycles.

The steel tensile ultimate strength is $\sigma_{\text {uts }}=650 \mathrm{MPa}$, and the fatigue limit $\left(\sigma_{\mathrm{f}}\right)$ is assumed to be half of the ultimate tensile strength $\left(\sigma_{\mathrm{uts}}\right)$, equation 1 . The analysis presented can be used for another steel just accounting for the relation mentioned, valid provided $\sigma_{\text {uts }}$ is lower that approximately $1300 \mathrm{MPa}$, (see e.g. [5]).

$$
\sigma_{f} \approx \frac{1}{2} \sigma_{u t s}
$$

Figure 1a presents the $U$ spring, where the distance from the axes of the cylinders to the plane of the built-in base of the spring (horizontal plane) is $34,56 \mathrm{~mm}$. The width of the strips subjected to bending is $21,5 \mathrm{~mm}$ and the thickness is $0,75 \mathrm{~mm}$.

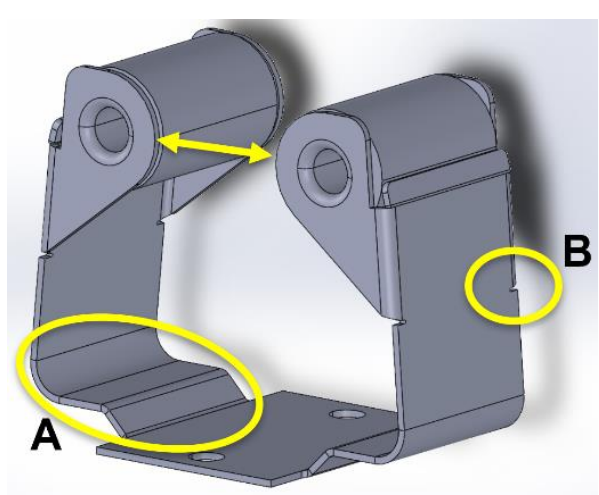

a) $3 \mathrm{D}$ model of the spring.

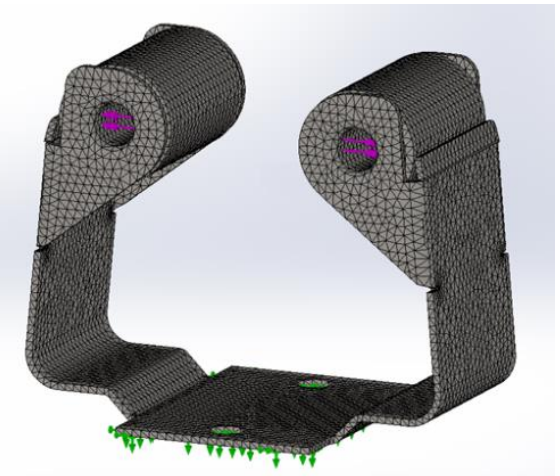

b) FEM mesh.

Fig. 1 - Spring studied, Solidworks.

Firstly, the spring stiffness (ratio force/displacement) must be known. The spring behaviour was modelled using the finite element method (FEM) software SolidWorks, leading to the numerical calculation of the stiffness. Before the actual FEM analysis of the chosen geometry, and to gain a preliminary perception of the stiffness, a simplified model using the same cross section $(21,5 \mathrm{~mm} \times 0,75 \mathrm{~mm})$ was evaluated, Figure 2, using Castigliano's theorem [6]. For this rough model, stiffness was $2 \times 1,4 / 10 \mathrm{~mm} / \mathrm{N}$. 


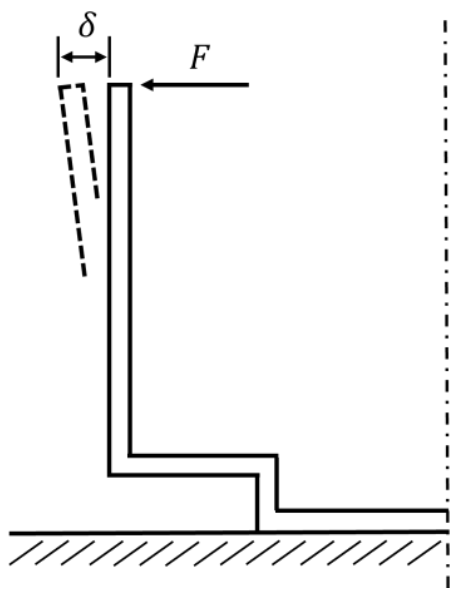

Fig. 2 - Simplified model, using symmetry.

The finite element mesh was generated and forces and boundary conditions were considered, Figure 1b. As a result of the preliminary approximate study using Castigliano's theorem mentioned, opening forces of $10 \mathrm{~N}$ were chosen to evaluate stiffness using FEM. These forces in the horizontal direction were applied in the axes of the spring cylinders. The lower part of the spring (horizontal plane) was built-in. A linear model was used in the finite elements analysis, as an approximation. The resulting displacement and stress maps are given in Figure 3.

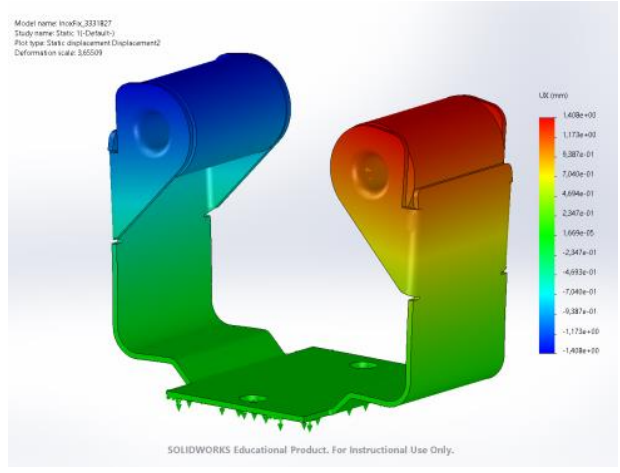

a) Displacement field

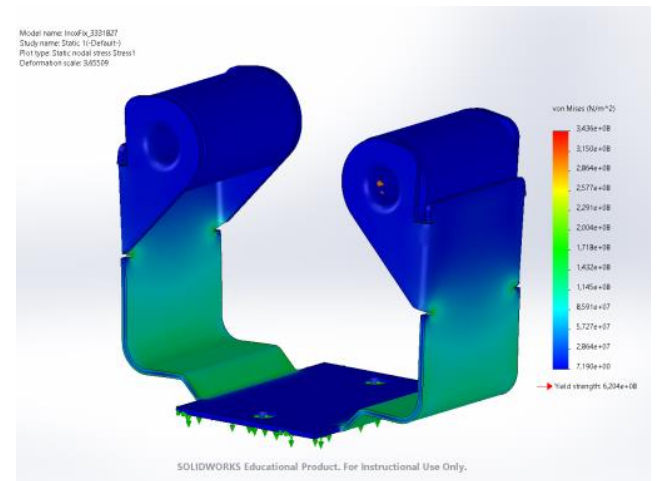

b) Stress field (von Mises)

Fig. 3 - FEM results for an opening load of $10 \mathrm{~N}$.

Considering half of the spring, due to symmetry, for a force of $10 \mathrm{~N}$ a horizontal displacement of $1,408 \mathrm{~mm}$ was found, and in region A (the region subjected to greater bending moments, see Figure 1a) maximum von Mises stress was $175 \mathrm{MPa}$. Although this is an equivalent stress, in the bent part of the spring the stress state is purely uniaxial, and the von Mises value is therefore a uniaxial stress value. It is noticed that the simplified geometry and calculation based upon Castigliano's theorem gave very similar stiffness results. Figure 4 displays the stress along the upper and lower surfaces of the region $\mathrm{A}$, where bending 
moment values are higher. In this figure the horizontal axis corresponds to distance to the plane of symmetry of the spring.

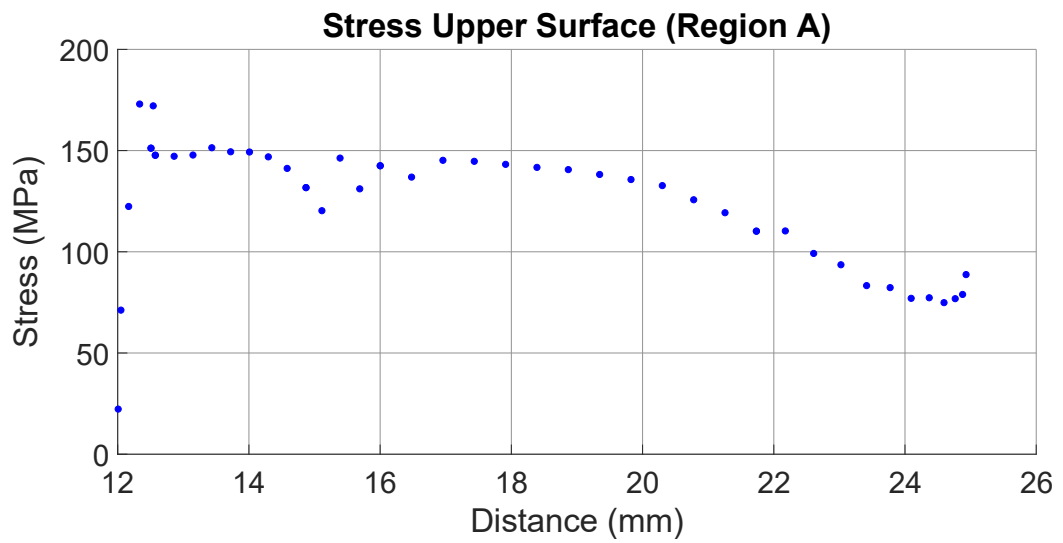

a)

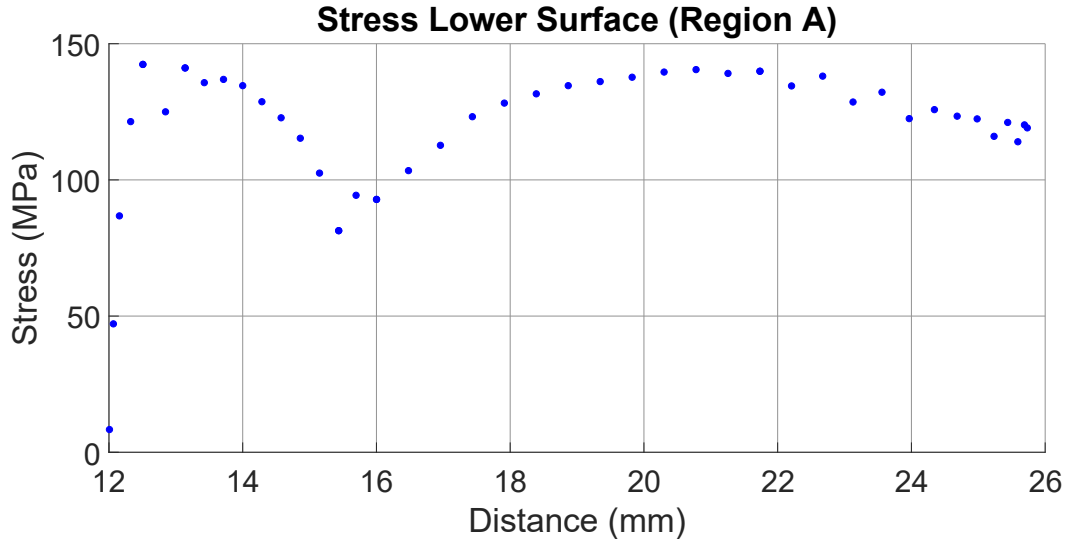

b)

Fig. 4 - Stress along upper and lower surfaces of region A (Fig. 1a), von Mises. Horizontal axis: distance to the axis of symmetry of the spring. a) upper surface. b) lower surface.

If the properties of the study are changed from 'Compute Free Body' to 'Large Displacement', and 'FFEPlus' to 'Direct Sparse Solver', so that Solidworks can be run in situations where the behavior of the part is not linear elastic, a displacement of 1,432 $\mathrm{mm}$ was obtained, rather close to the linear elastic value of $1,408 \mathrm{~mm}$.

\section{Fatigue analysis}

Once the spring stiffness was characterized, a fatigue analysis followed in order to evaluate the maximum opening compatible with a service life of at least 240 kcycles, which is the requirement of the present real life case study. The FEM linear elastic analysis slightly underpredicts the displacement, and was adopted as being a conservative approximation.

The classical analysis presented e.g. in the machine design treatise of Juvinall and Marshek [7] was adopted for the fatigue study. This involves the Basquin law and Goodman diagram, and the relationship between ultimate tensile strength and fatigue limit. Firstly, the 
SN curve for zero mean stress (i.e. stress ratio $R=\sigma_{\min } / \sigma_{\max }=-1$ ) was constructed using the points $\left(10^{3}\right.$ kcycles, $\left.\sigma_{\mathrm{a}}=0,9 \times \sigma_{\text {uts }}\right)$ and $\left(10^{6} \mathrm{kcycles}, \sigma_{\mathrm{a}}=0,5 \times \sigma_{\text {uts }}\right)$. The Basquin law was used to plot the inclined straight line of Figure 5. It was then possible to evaluate a stress amplitude of $365 \mathrm{MPa}$ corresponding to 260 kcycles.

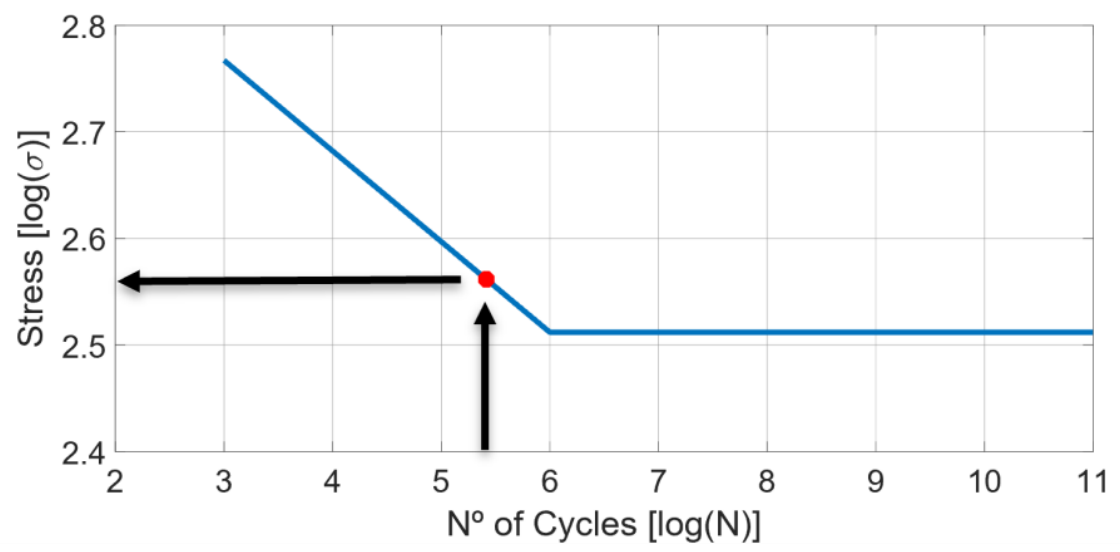

Fig. 5 - SN curve, $R=-1$

This corresponds to a zero mean stress situation $(R=-1)$ which is not directly applicable to the case under consideration. The spring is either loaded by an imposed displacement, or it is load free; therefore, the stress (or load) ratio $R$ is null in the present case. Diagrams for finite life can be derived using the $R=-1$ data already presented: in a stress amplitude versus mean stress $\left(\sigma_{\mathrm{a}}\right.$ versus $\left.\sigma_{\mathrm{m}}\right)$ plot the $R=-1$, finite life data points coming from Figure 5 $\left(\sigma_{\mathrm{a}, \mathrm{N}, \mathrm{R}=-1}\right)$ are plotted in vertical axis, and connected to $\sigma_{\mathrm{m}}=\sigma_{\mathrm{uts}}$ as generally presented in lower part of Figure 6.

Because $R=-1$ it is $\sigma_{\mathrm{a}}=\sigma_{\mathrm{m}}=0,5 \times \sigma_{\max }$. In equation 2 .

$$
\frac{\sigma_{a}}{\sigma_{a, N, R=-1}}+\frac{\sigma_{m}}{\sigma_{u t s}}=\frac{1}{S . F .}
$$

the safety factor (S.F.) used was 1,2, and the fatigue limit correction factors (surface, size etc.) in the fatigue limit amounted to 0,8 . Finally a value of $\sigma_{\mathrm{a}}=\sigma_{\mathrm{m}}=168 \mathrm{MPa}$ was calculated, corresponding to a maximum applied stress per cycle of $2 \times 168=336 \mathrm{MPa}$.

Going back to the FEM analysis, from linearity it is concluded that the load creating this stress in region (Figure 1a) is 19,2 N, corresponding to a displacement of 2,703 mm. Given the symmetry, therefore the overall displacement that creates the maximum stress $336 \mathrm{MPa}$ is $2 \times 2,703 \mathrm{~mm}=5,406 \mathrm{~mm}$. 


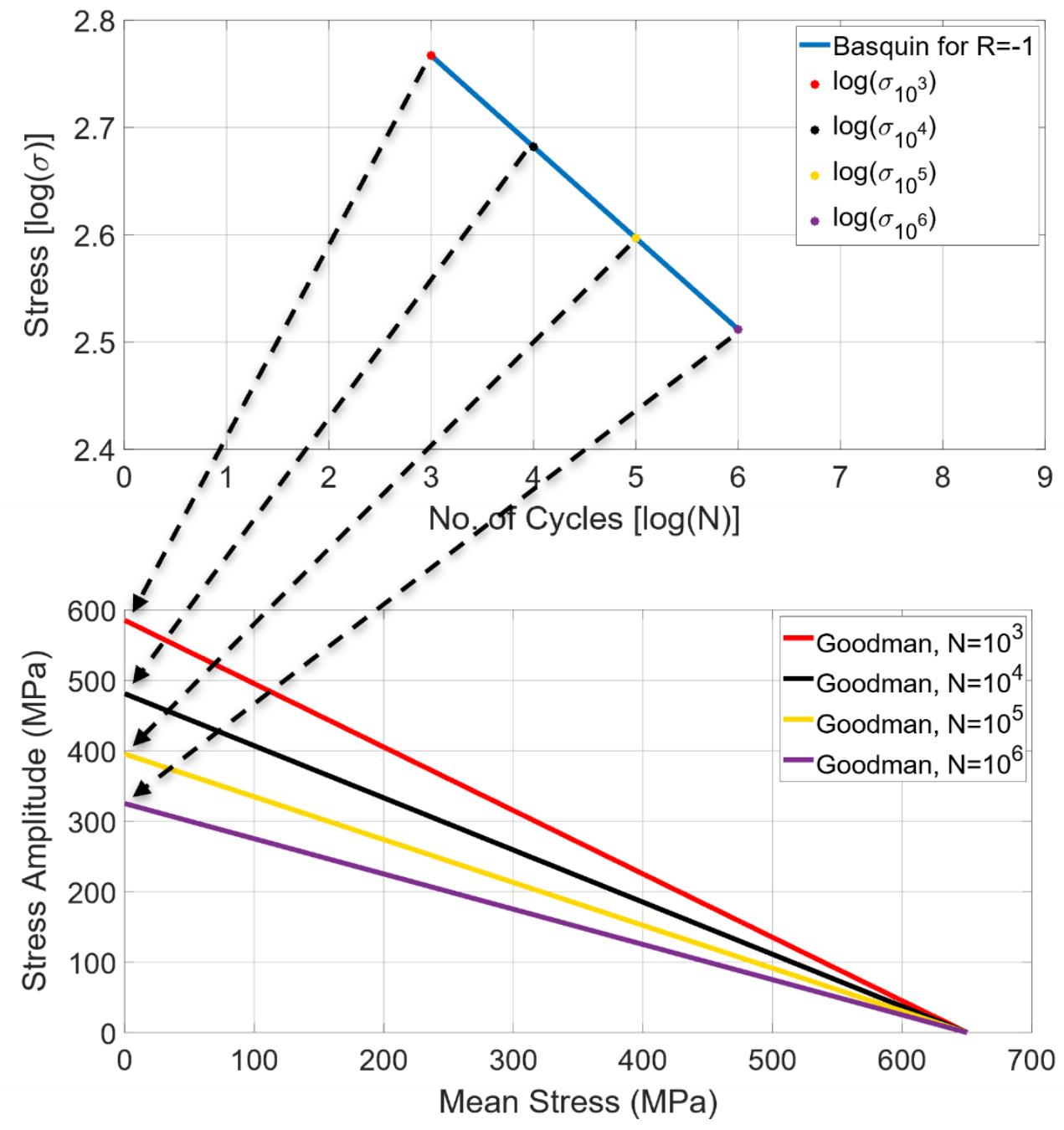

Fig. 6 - Mean stress effect, using Basquin SN curve for $R=-1$ and Goodman diagram.

Although the calculation was performed for steady cyclic loading with constant load range and $R$ ratio, the analyses are easily extended to variable amplitude loading. Also, the stress analysis helped to highlight the need for some minor geometry changes: at the notch, region $\mathrm{B}, \sigma_{\max }=660 \mathrm{MPa}$, but this is of no concern since this notch (resulting from the manufacturing process initially envisaged) will disappear in local redesign of this region, which is subjected to low bending moment.

Should a greater displacement be required in service, the presented algorithm would readily analyze the problem for a steel with higher $\sigma_{\text {uts }}$. Further aspects as enhancement of fatigue strength e.g. via shot-peening are not addressed here, but it is recognized that the creation of surface negative residual stresses would improve the fatigue strength, allowing if necessary the use of a greater displacement in service. This conference includes a detailed discussion of the shot peening benefits in a different type of spring, see [8-9]. 


\section{Concluding remarks}

The presentation illustrates a case study of durability using classical HCF concepts, together with results of a FEM analysis. The outcome of the study was the evaluation of the maximum permissible displacement per cycle compatible with a certain fixed number of cycles required in the real life case addressed.

\section{References}

1. Dean Harris, T. Jur, 'Classical Fatigue Design Techniques as a Failure Analysis Tool', J Fail. Anal. and Preven., vol.9, pp.81-87, (2009). DOI 10.1007/s11668-008-9202-1

2. Yung-Li Lee, Mark E. Barkey, 'Stress-Based Uniaxial Fatigue Analysis', chapter 4 of: Yung-Li Lee, Mark E. Barkey, Hong-Tae Kang, 'Metal Fatigue Analysis Handbook: Practical Problem-Solving Techniques for Computer-Aided Engineering', Waltham, MA: Butterworth-Heinemann / Elsevier, pp.115-160, (2012)

3. Yung-Li Lee, Darryl Taylor, 'Stress-Based Fatigue Analysis and Design', chapter 4 of: Yung-Li Lee, Jwo Pan, Richard B. Hathaway, Mark E. Barkey, 'Fatigue Testing and Analysis (Theory and Practice)', Burlington, MA: Elsevier / Butterworth-Heinemann, pp.103-180, (2005)

4. Pietro Paolo Milella, 'Fatigue and Corrosion in Metals', Springer-Verlag Italia, (2013). (particularly chapter 5, pp.245-308)

5. James A. Graham, John F. Millan, Franklin J. Appl, 'Fatigue Design Handbook', New York, NY: Society of Automotive Engineers, (1968)

6. Harold Josephs and Ronald L. Huston, 'Practical Stress Analysis in Engineering Design', 3rd ed., Boca Raton, FL: CRC Press / Taylor \& Francis Group, (2009)

7. Robert C. Juvinall, Kurt M. Marshek, 'Fundamentals of Machine Component Design', 6th ed., Hoboken, NJ: John Wiley \& Sons, (2017). (particularly chapter 8: 'Fatigue', pp.287-340)

8. M. Pappa, G. Savaidis, N. Michailidis, 'Characterization of surface integrity of shotpeened leaf springs by micro- and nano-indentation', 6th International Virtual Conference of Engineering Against Failure, E-Book of Abstracts, \#232, (2021)

9. M. Malikoutsakis, C. Gakias, I. Makris, P. Kinzel, E. Müller, M. Pappa, N. Michailidis, G. Savaidis, 'On the effects of heat and surface treatment on the fatigue performance of high-strength leaf springs', 6th International Virtual Conference of Engineering Against Failure, E-Book of Abstracts, \#51, (2021) 